both the NR animals $(\mathrm{t}=2.29, \mathrm{df}=20, \mathrm{p}<.05)$ and the PR animals $(\mathrm{t}=2.24, \mathrm{df}=20, \mathrm{p}<.05)$. The CR vs NR difference was also significant on the second trial of extinction $(\mathrm{t}=2.11, \mathrm{df}=20, \mathrm{p}<.05)$. The large rise in activity did not persist, however, as no apparent differences between groups were seen after the third extinction trial. The NR and PR groups did not significantly differ in extinction.

\section{DISCUSSION}

These results are substantially in agreement with the previously mentioned studies in supporting the contention that a frustration response following nonreinforcement within the context of reinforcement will manifest itself in increased activity or "agitated" behavior, as first suggested by Miller \& Stevenson (1936). However, the increase in activity on nonreinforced trials during acquisition for PR animals, when compared to NR animals, was not as strong as that reported by Dunlap et al (1971).

The failure of the increased activity of the CR animals to persist beyond the first few trials of extinction is in agreement with the observation of Tacker \& Way (1968), and suggests that the activity changes observed here represent only the initial transient emotional reaction to a frustrating situation and do not index the frustration responses presumed to be affecting response persistence in multiple-trial situations. The failure of the PR group to differ from the NR group in extinction is consistent with the typical frustration theory explanation of the partial reinforcement effect in extinction, namely, that PR experience in acquisition precludes a major interfering frustration reaction during consistent nonreinforcement (extinction).

\section{REFERENCES}

Amsel, A., \& Roussel, J. Motivational properties of frustration: I. Effect on a running response of the addition of frustration to the motivational complex. Journal of Experimental Psychology, 1952, 43, 363-368.

Dunlap, W. P., Hughes, L. F., O'Brien, T. J., Lewis, J. H., \& Dachowski, L. Goalbox activity as a measure of frustration in a single runway. Psychonomic Science, 1971, 23, 327-328.

Gallup, G. G., Jr., \& Altomari, T. S. Activity as a post situation measure of frustrative nonreward. Journal of Comparative \& measure of frustrative nonreward. Journal of
Physiological Psychology, 1969, 68, 382-384.

Gallup, G. G., Jr., \& Hare, G. K. Activity following partially reinforced trials: Evidence for a residual frustration effect due to conditioned frustration. Psychonomic Science, 1969, 16, 41-42.

McHose, J. H., \& Ludvigson, H. W. Differential conditioning with nondifferential reinforcement. Psychonomic Science, $1966,6,485-486$.

Miller, N. E., \& Stevenson, S. S. Agitated behaviour of rats during experiment extinction and a curve of spontaneous recovery. Journal of Comparative Psychology, 1936, 21, 205-231.

Scull, J. W. The Amsel frustration effect: Interpretations and research: Psychological Bulletin, 1973, $7^{\circ}, 352361$.

Tacker, R. S., \& Way, J. Motivational pro srties of nonreward. Psychonomic Science, 1968, 10, 103-104

Topping, J. F., Cole, J. M., Matamoros, M. I . \& Linenberger, G. H. Motivational effects of differe magnitudes of reinforcement. Psychonomic Science, 197C, 19, 25-26.

Wagner, A. R. The role of reinforcement and nonreinforcement in an "apparent frustration effect." Journal of Experimental Psychology, 1959, 57, 130-136.

Wasserman, E. A., \& Jensen, D. D. Olfactory stimuli and the "pseudo-extinction" effect. Science, $1969,166,1307-1309$.

(Received for publication November 9, 1973.)

Bulletin of the Psychonomic Society

1974, Vol. 3 (3A), 174-176

\title{
Activity level and secondary motivation: Incentive
}

\section{WARREN F. KLARE}

Syracuse University, Syracuse, N.Y. 13210

Activity level was monitored in the startbox before a runway trial for a group of eight rats running for food reward, and for a second group of eight rats receiving identical treatment but with no reward given. There was no evidence for an excitatory incentive response, as the groups' activity levels did not differ during acquisition. In extinction, the previously rewarded animals were more active, suggesting a frustration effect.

Hull (1952) and Spence (1956) have suggested that an incentive response is conditioned when neutral stimuli are paired with consummatory responding. The subsequent elicitation of this learned response leads to an increment in motivation. Spence then went on to explain instrumental runway behavior in terms of this secondary motivation. There have been numerous reports consistent with Spence's suggestion, including a series of studies showing an increase in activity level following the presentation of a stimulus which had been paired with food (e.g., Sheffield \& Campbell, 1954; Bind ra \& Palfai, 1967; Zamble, 1967). However, several investigators have reported an apparent demotivational effect of a stimulus paired with food (e.g., Trapold, 1962; Armus \& Sniadowski-Dolinsky, 1966). Several theorists have suggested that since the consummatory response to a goal stimulus is usually demotivating, it is most consistent to assume that the learned response based on it also be demotivational (Bolles, 1967; Brown \& Farber, 1968).

Spence originally used the incentive-motivation notion to explain runway behavior, with the generalization of the responding to startbox cues initiating the running response. However, all of the studies referenced above have been performed in other types of situations. This study attempts assessment of changes in activity level in the startbox of a food-reward runway, as this would seem to be an appropriate addition to the currently available information.

A second, quite unrelated reason exists for the present study. Klare (1974) has argued that a measured decline in activity in the startbox of a shock-escape runway is due to fear-induced freezing. However, an alternative possibility is that the decline in activity is due to preparatory responses to facilitate running on the part of the shocked Ss. In the present study, the level of activity in the startbox was compared between Ss receiving food reward for running in the runway and the Ss not receiving reward, and thus not running. Significant activity reductions for food-reward Ss could be interpreted as due to preparatory responses to facilitate 
Fig. 1. Mean startbox activity level for rewarded (R) and nonrewarded (NR) Ss across trials in acquisition and extinction.

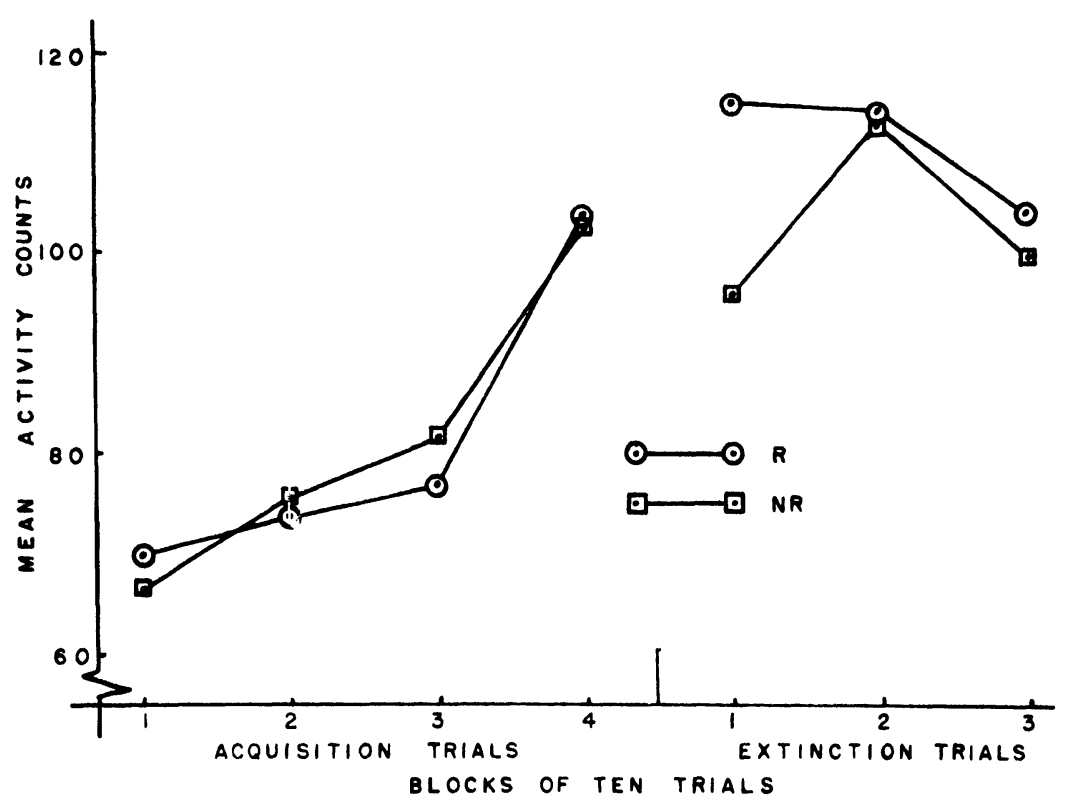

rapid running, which would question the validity of such changes in activity as indexes of conditioned fear.

\section{METHOD}

\section{Subjects}

The Ss were 16 female hooded rats, 90-120 days old, of the Long-Evans strain from the colony maintained by the Department of Psychology at Syracuse University. They were housed in individual cages and put on a deprivation schedule to reduce them to approximately $85 \%$ of their adjusted normal body weights before training trials were begun.

\section{Apparatus}

The apparatus consisted of a straight dark gray grid-floor runway $(106 \mathrm{~cm}$ long $\times 11.5 \mathrm{~cm}$ wide $\times 20 \mathrm{~cm}$ high), with a bent metal spoon affixed to the end wall to serve as a foodcup. A dark gray chamber $(30 \mathrm{~cm}$ long $\times 11.5 \mathrm{~cm}$ wide $\times 17 \mathrm{~cm}$ deep) was attached above the start end of the runway. All sections had Plexiglas lids. An Alton Electronics ultrasonic motion detector (Model 4) was mounted to monitor activity levels in the chamber above the startbox, with total number of output pulses recorded on a Hunter Klockounter.

\section{Procedure}

After the Ss reached the required deprivation level, they were allowed to explore the runway for $10 \mathrm{~min}$ on one day. The following day, training began, with eight animals receiving approximately $300 \mathrm{mg}$ of wet mash on each of five trials per day, while the remaining animals received identical handling but no reward. A trial consisted of placement into the chamber over the startbox, where activity was monitored for a 10 -sec period. Following that, the trap-door floor of the box was released, dropping the animal to the floor of the runway. Each animal was allowed $30 \mathrm{sec}$ to consume the reward. It was then removed and placed in a holding cage while the runway was cleaned and reset and the data recorded. The intertrial interval was approximately $1 \mathrm{~min}$ for all Ss. Acquisition trials were continued for 8 days (a total of 40 trials), and then 6 more days of extinction trials (no animals receiving reward) were run.

\section{RESULTS}

Activity scores were blocked over 10 trials, and the mean scores for both groups in acquisition and extinction are presented in Fig. 1. During acquisition, there were clearly no differences between rewarded and nonrewarded Ss in the startbox activity. In extinction, the animals that had been rewarded initially appeared more active. This difference reached statistical significance on the first block of nonrewarded trials $(\mathrm{t}=$ 2.80 , df $=14, p<.05)$, but was almost completely dissipated in subsequent blocks.

\section{DISCUSSION}

The significant difference between groups on the first block of extinction trials clearly suggests a frustration effect generalizing to the startbox. This is quite similar to effects already reported in goalbox activity (e.g., Dunlap, Hughes, O'Brien, Lewis, \& Dachowski, 1971). The transient nature of the effect also agrees with previous activity-level changes reported in extinction (Scull, 1973).

In contrast to the extinction results, there was no evidence confirming the appearance in the startbox of the hypothesized secondary motivational incentive response. The fact that activity changes have occurred in the startbox for the secondary motivational responses of frustration (in this study) and fear (Klare, 1974) suggests that such a failure is not due to the use of a separate but connected activity chamber in the startbox or to the experimental procedures used. Thus, while it is most inappropriate to draw a firm conclusion from a finding of no significant differences, the above facts suggest that this lack of a difference cannot be easily dismissed.

The second question raised in introducing this study, that of the possible role of preparatory responses on activity level, received a clearer response from these results. There was no evidence that animals running rapidly in the runway (i.e., the rewarded group) become less active before the trapdoor drops, as would be expected if they were aligning themselves in the direction of the goal and then waiting quietly. Apart from the improbable (though tenable) suggestion that there is an incentive-induced increase in activity exactly matched by a preparatory-response-induced decrease in activity, these data support the conclusion that the reduced activity appearing in the startbox when aversive stimuli are used in the runway is adequately explained in terms of freezing in response to fear-arousing stimuli. 


\section{REFERENCES}

Armus, H. L., \& Sniadowski-Dolinsky, D. Startle decrement and secondary reinforcement stimulation. Psychonomic Science 1966, 4, 175-176

Bindra, D., \& Palfai, T. Nature of positive and negative incentive-motivational effects on general activity. Journal of Comparative \& Physiological Psychology, 1967, 63, 288-297.

Bolles, R. C. Theory of motivation. New York: Harper \& Row, 1967.

Brown, J. S., \& Farber, I. E. Secondary motivational systems. Annual Review of Psychology, 1968, 19, 99-134.

Dunlap, W. P., Hughes, L. F., O'Brien, T. J., Lewis, J. H., \& Dachowski, L. Goalbox activity as a measure of frustration in a single runway. Psychonomic Science, 1971, 23, 327-328.

Hull, C. L. A behavior system. New Haven: Yale University Press, 1952.

Klare, W. F. Activity level and secondary motivation: Fear.
Bulletin of the Psychonomic Society, 1974, 3, 171-172. Scull, J. W. The Amsel frustration effect: Interpretations and reasearch. Psychological Bulletin, 1973, 79, 352-361.

Sheffield, F. D., \& Campbell, B. A. The role of experience in the "spontaneous" activity of hungry rats. Journal of Comparative \& Physiological Psychology, 1954, 47, 97-100. Spence, K. W. Behavior theory and conditioning. New Haven: Yale University Press, 1956.

Trapold, M. A. The effect of incentive motivation on an unrelated reflex response. Journal of Comparative \& Physiological Psychology, 1962, 55, 1034-1039.

Zamble, E. Classical conditioning of excitement anticipatory to food reward. Journal of Comparative \& Physiological Psychology, 1967, 63, 526-529.

(Received for publication November 9, 1973.) 